\title{
Sequence, genetic analysis, and expression of Actinobacillus pleuropneumoniae transferrin receptor genes
}

\author{
Guido C. Gonzalez, ${ }^{1}$ Rong-hua Yu, ${ }^{1}$ Paul R. Rosteck, Jr ${ }^{2}$ \\ and Anthony B. Schryvers ${ }^{1}$ \\ Author for correspondence: Guido C. Gonzalez. Tel: +1 403220 6047. Fax: +1 4032838814.
e-mail: ggonzale@acs.ucalgary.ac
}

1 Department of

Microbiology and

Infectious Diseases,

University of Calgary, 3330

Hospital Drive NW,

Calgary, AB T2N 4N1,

Canada

2 Lilly Research Laboratories, Indianapolis, IN, USA
The tbpA and tbpB genes encoding the transferrin receptor proteins Tbp1 and Tbp2 from a serotype 7 strain of Actinobacillus pleuropneumoniae were cloned, sequenced, and expressed in Escherichia coli. The thpB gene was preceded by putative promoter and regulatory sequences and was separated from the downstream tbpA gene by a 13 bp intercistronic sequence suggesting that the two genes may be coordinately transcribed. Determination of the nucleotide sequence of this region facilitated PCR amplification of the tbp region from a serotype 1 strain for comparative purposes. The deduced amino acid sequences of the Tbp1 proteins had regions of homology with Neisseria Lbp and Tbp1s and with TonB-dependent outer membrane (OM) receptors of $E$. coli. The deduced amino acid sequences of the Tbp2 proteins were nearly identical to those presented in previous studies. Upon high-level expression of the tbpA gene, a large proportion of the recombinant Tbp1 was found in inclusion bodies and could not be affinity-isolated with immobilized porcine transferrin. Most of the remaining expressed Tbp1 was present in the OM fraction, was expressed at the surface of $E$. coli cells, and retained binding activity that was specific for the C-lobe of porcine transferrin. Although recombinant Tbp2 was found in inclusion bodies during high-level expression, a significant proportion was associated with a novel $O M$ fraction that appeared in sucrose density gradients which was distinct from the OM fraction containing recombinant Tbp1. The recombinant Tbp2 was accessible at the surface yet was unable to bind porcine transferrin. In contrast to previous observations, the binding by recombinant Tbp2 was specific for the C-lobe of porcine transferrin. These results indicate that the A. pleuropneumoniae transferrin receptor proteins have similar properties to the receptor proteins in Neisseria spp. and Haemophilus influenzae, and that functional studies performed with recombinant receptor proteins need to consider differences in processing and export of these proteins when expressed in heterologous hosts.

Keywords: transferrin receptor proteins, transferrin receptor genes, Actinobacillus pleuropneumoniae, affinity-isolation

\section{INTRODUCTION}

Acquisition of iron in the iron-restricted environment of

Abbreviations: IM, inner membrane; OM, outer membrane; PVDF, polyvinylidine difluoride.

The GenBank accession numbers for the nucleotide sequence of the tbpB/A region from strains $h 49$ and $h 171$ are U16017 and U16019, respectively. the host is an essential capability for many bacterial pathogens (Weinberg, 1978). Studies with pathogenic Neisseria spp. (Archibald \& DeVoe, 1979; Griffiss, 1982; Mickelsen et al., 1982; Simonson et al., 1982) demonstrated that these bacteria acquire iron from the host's iron-sequestering glycoproteins, transferrin and lactoferrin, using a mechanism involving direct binding of the glycoprotein by surface receptors. Binding studies, 
affinity-isolation experiments and genetic analysis have demonstrated that the transferrin and lactoferrin receptors are distinct and specific for glycoproteins from the host (Schryvers \& Morris, 1988a, b; Blanton et al., 1990; Cornelissen et al., 1992; Pettersson et al., 1994b). The presence of transferrin receptors in a variety of other Gram-negative bacterial species that are pathogenic to man and other animals (Schryvers \& Lee, 1989; Ogunnariwo \& Schryvers, 1990, 1992; Gonzalez et al., 1990; Schryvers \& Gray-Owen, 1992) indicates that this receptor-mediated mechanism of iron acquisition is fairly widespread.

Affinity-isolation experiments suggest that the lactoferrin receptor consists of a $105 \mathrm{kDa}$ iron-repressible outermembrane protein whereas the transferrin receptor is composed of two iron-repressible outer-membrane proteins, Tbp1 and Tbp2 (Schryvers et al., 1991). Tbp1 is accessible at the surface, is required for iron acquisition from transferrin and, based on localized sequence homology, is proposed to be a transmembrane protein related to TonB-dependent receptors (Cornelissen et al., 1992; Irwin $e t$ al., 1993; Legrain et al., 1993; Gray-Owen $e t$ al., 1995). Tbp2 is also accessible at the surface and appears to be a lipoprotein presumably anchored in the membrane by its lipid tail (Irwin et al., 1993; Legrain et al., 1993). In Neisseria meningitidis, Tbp2 appears to be required for iron acquisition from transferrin (Irwin et al., 1993), whereas in Neisseria gonorrboeae and Haemopbilus infuenzae it may be important but not essential for this process (Gray-Owen $e t$ al., 1995; Anderson et al., 1994). The N. meningitidis lactoferrin receptor protein, $\mathrm{Lbp}$, is presumed to be a transmembrane protein due to its homology with TonBdependent receptors and Tbp1 (Pettersson et al., 1993).

The genes encoding the transferrin receptor proteins in $N$. meningitidis, $N$. gonorrboeae and $H$. influenzae appear to be in an operon with putative promoter and regulatory regions preceding the $t b p B$ gene (encoding Tbp2) which is followed by the $t b p A$ gene (encoding Tbp1) after an intercistronic region ranging from $13 \mathrm{bp}$ (Gray-Owen et al., 1995) to 70-80 bp (Legrain et al., 1993; Anderson et al., 1994). Although initial reports on the analysis of the $\operatorname{lbp} A$ gene suggested differences from the $t b p$ region (Pettersson et al., 1993), it has recently been reported that there may be a similar operon arrangement with a gene encoding a Tbp2 homologue upstream of the $l b p A$ gene (Pettersson et al., 1994a). Several recent studies have demonstrated that expression in $E$. coli of the meningococcal tbp $A$ gene (Palmer et al., 1993), the gonococcal tbpA gene (Cornelissen et al., 1993) or the meningococcal lbp $A$ gene (Pettersson et al., 1994b) resulted in transferrin- or lactoferrin-binding activity at the surface of the cell. These results suggest that the Neisseria Tbp1 and Lbp proteins are properly processed and exported in the heterologous $E$. coli: this has important implications for functional studies with the recombinant proteins.

The transferrin receptor in the porcine pathogen, Actinobacillus pleuropneumoniae, is similarly composed of two proteins, Tbp1 and Tbp2, and is specific for porcine transferrin (Gonzalez et al., 1990). The genes encoding the Tbp2 ( $\mathrm{TfbA}$ ) proteins from two strains of $A$. pleuropneumoniae have been cloned and characterized (Gerlach $e t$ al., 1992a, b) but these experiments did not include information on the presence of the $\operatorname{tbp} A$ genes or the organization of the $t b p$ genes. The recombinant $\mathrm{Tbp} 2$ proteins produced upon expression of two $t f b A(t b p B)$ genes have been tested for efficacy as vaccine antigens (Rossi-Campos et al., 1992). The recombinant Tbp2 protein was produced primarily as an inclusion body and the reconstituted recombinant Tbp2 was reported to have several features that appeared to distinguish it from the receptor in Neisseria spp., including a preference for the iron-saturated form of the protein, an ability to bind the $\mathrm{N}$-lobe of porcine transferrin and an ability to bind haemin (Gerlach et al., 1992a). In this study, we report the cloning, sequencing and expression of $t b p A$ and $t b p B$ genes from $A$. pleuropneumoniae and we compare the binding properties of the expressed recombinant proteins with the native receptor.

\section{METHODS}

Bacterial strains and growth conditions. A. pleuropneumoniae strains h49 and h171 are serotype 7 and serotype 1 clinical disease isolates obtained from S. Lundberg (Veterinary Laboratory, Regional Agricultural Building, Airdrie, AB, Canada) and E. Ose (Lilly Research Laboratories, Veterinary Division, Greenfield, IN, USA), respectively. The genotype and phenotype of the E. coli host strains SURE and BL21 are described by Greener (1990) and Studier et al. (1990), respectively. All bacterial strains were stored frozen at $-70^{\circ} \mathrm{C}$ in $30 \%(\mathrm{v} / \mathrm{v})$ glycerol. E. coli was cultured in Luria broth (LB) or on LB agar plates with the required antibiotic. Incubation of all bacterial strains was for $16-20 \mathrm{~h}$ at $37^{\circ} \mathrm{C}$. Growth conditions for expression using IPTG-induction or CE6 infection are described elsewhere (Studier et al., 1990).

Production of antisera for library screening and expression procedures. Three antisera were produced in rabbits using approximately $500 \mu \mathrm{g}$ protein along with complete Freund's adjuvant for the first immunization and incomplete adjuvant for subsequent boosting of the antigen (Harlow \& Lane, 1988). Whole receptor antiserum was raised against transferrin receptor complex (Tbp1 and Tbp2) isolated from A. pleuropneumoniae strain h49 (Gonzalez et al., 1990). This antiserum was primarily reactive against $\mathrm{Tbp} 2$. Tbp1- and Tbp2-specific antisera were raised against the electroeluted proteins. All antisera were used in a range from $1 / 500$ to $1 / 40000$ dilutions in the assay buffer. To block possible E. coli-directed antibodies, lysates of the host SURE or BL21 strains were used in the screening of the recombinant Lambda Zap II phage genebank or in the expression procedure, respectively.

Recombinant phage genebank and plasmids. The recombinant genebank was prepared by ligation of $6-10 \mathrm{~kb}$ fragments of randomly sheared $A$. pleuropneumoniae h49 chromosomal DNA with EcoRI-digested Lambda Zap II DNA (Short et al., 1988), following EcoRI methylase treatment and the addition of EcoRI linkers. After producing recombinant phage particles by treatment of the ligated DNA with lambda packaging extracts, the library was screened by using whole h49 receptor antiserum. Conversion of the antiserum-positive recombinant Lambda Zap II clones to a pBluescriptII SK(+) plasmid was done by co-infecting strain SURE with both the 
lambda vector and $\mathrm{f1}$ phage VCSM13 by in vivo excision (Short et al., 1988).

Plasmid pT7APT1 was constructed by PCR amplification of a strain h49 genomic DNA fragment flanked by primers 042 ( $t b p A 5^{\prime}$ end) and 043 ( $t b p A 3^{\prime}$ end, Table 1), insertion of the fragment into the $\mathrm{PCR}$ II vector (Invitrogen) and final insertion into the NdeI and HindIII sites of the PT7-7 vector (Tabor, 1992). Similarly, pT7APT2 was produced by PCR amplification of h49 genomic DNA using primers 044 ( $t b p B 5^{\prime}$ end) and 045 $\left(t b p B 3^{\prime}\right.$ end) followed by cloning into the $\mathrm{p} T 7-7$ vector as described above. Plasmid p'T7APT21 was constructed by direct insertion of an EcoRI/XhoI fragment from pBAPT11 (see Results), containing both $t b p A$ and $t b p B$, into the EcoRI and Sall sites of pT7-7.

DNA sequencing. Sequencing was performed with the purified pBAPT1 and pBAPT2 recombinant plasmids by the oligonucleotide primer-directed procedure using synthetic oligonucleotides, fluorescent-dye-labelled dNTP terminators, and cycle sequencing with Taq polymerase. Sequence reaction products were analysed on Applied Biosystems (ABI) model $373 \mathrm{~A}$ automated fluorescent sequencers. Individual sequence reads were assembled into contigs and edited on the ABI Inherit sequence analysis system, a parallel process computer workstation for sequence assembly, editing and analysis. Computeraided analysis of the nucleotide sequence was with the GCG suite of programs.

Oligonucleotide synthesis. The oligonucleotides described in Table 1 were designed taking into account the $5^{\prime}$ and $3^{\prime}$ flanking

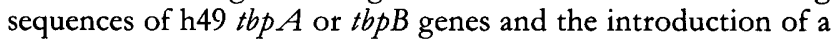
$N d e I$ ( $5^{\prime}$ end) and a HindIII ( $3^{\prime}$ end) restriction site for direct cloning into the $\mathrm{pT} 7-7$ vector. Synthesis of the primers was performed by the phosphoramidite method using an ABI model 391 DNA synthesizer. They were used directly after purification using Waters Sep-Pak Plus C18 cartridges.

Expression of recombinant Tbp1 and Tbp2. Expression of the tbp genes in the recombinant $\mathrm{pBluescript}$ plasmids was induced by the addition of IPTG.

PCR-amplified coding sequences for the $t b p B$ and $t b p A$ genes from strain h49 were introduced into a $N d e I / H i n d I I I-d i g e s t e d$ pT7-7 vector producing p'T7APT1 and p'T7APT2 (Fig. 1). In these constructs the start codon is positioned such that both the promoter and the RBS are provided by the vector. For expression of both receptor proteins, the $t b p B / A$ region from pBAPT11, which includes the putative native promoter and the RBS, was subcloned into pT7-7 to produce pT7APT21. The recombinant plasmids were transformed into strain BL21, a host strain that contains mutations in two host proteases, and expression of the tbp genes was achieved by infection of midexponential-phase cultures of BL21 carrying the recombinant pT7-7 with the CE6 lambda phage which carries the T7 RNA polymerase gene (Studier et al., 1990). Incubation before harvesting was for $2 \mathrm{~h}$ at $37^{\circ} \mathrm{C}$ in a shaker incubator.

Cell fractionation. Whole cells and whole-cell lysates were prepared from BL21, BL21/pT7APT1 or BL21/pT7APT2 cells. Harvested cells were resuspended in ice-cold $50 \mathrm{mM}$ Tris/ $\mathrm{HCl}, \mathrm{pH} 7.5$, and immediately spotted onto $\mathrm{HA}$ paper (nitrocellulose/cellulose acetate membrane, Millipore). After addition of PMSF to $1 \mathrm{mM}$, lysates were obtained by sonicating with a Braunsonic 1510 (B. Braun) sonicator at 50-100 W for three $10 \mathrm{~s}$ bursts at $4^{\circ} \mathrm{C}$. The lysates were applied to the HA paper immediately after sonication.

For the preparation of cell fractions for the experiments illustrated in Figs 5 and 6, 11 cultures of BL21/pT7APT1 (expressing Tbp1), or BL21/p'T7APT2 (expressing Tbp2), were infected with CE6 phage and harvested $2 \mathrm{~h}$ after infection. The cell pellets were resuspended in ice-cold $30 \mathrm{mM}$ Tris $/ \mathrm{HCl}$ $\mathrm{pH} 7.5$ containing the protease inhibitor 4-(2-aminoethyl)benzenesulfonylfluoride- $\mathrm{HCl}$ at $1 \mathrm{mM}$ final concentration. Whole-cell lysates were obtained by passage of the cell suspensions through a French pressure cell (16000 p.s.i.; $110.4 \mathrm{MPa}$ ) followed by the addition of $\mathrm{MgCl}_{2}$ (to $10 \mathrm{mM}$ ), DNase I and RNase A (to $50 \mu \mathrm{g} \mathrm{m}^{-1}$ ), and lysozyme (to $100 \mu \mathrm{g}$ $\mathrm{ml}^{-1}$ ). After removal of the pellet of cell debris by centrifugation at $12000 \mathrm{~g}$, the lysate was centrifuged at $170000 \mathrm{~g}$ for $1 \mathrm{~h}$ at $4{ }^{\circ} \mathrm{C}$. The supernatant was lyophilized, resuspended in a small volume of distilled water and stored at $-70^{\circ} \mathrm{C}$ for analysis of cytosolic/periplasmic proteins. The pellets, representing the total membrane fractions, were resuspended in distilled water and stored at $-70^{\circ} \mathrm{C}$. Inner and outer membrane fractions were obtained from a $52-70 \%(\mathrm{w} / \mathrm{v})$ sucrose density gradient after centrifuging at $180000 \mathrm{~g}$ by the method of Hancock \& Nikaido (1978). NADH oxidase assay was used to mark inner membranes (IMs) (Osborn et al., 1972). The limulus amoebocyte lysate assay for LPS as a marker for outer membrane (OM) was performed according to the manufacturer's protocol (Associates of Cape Cod).

Bands were collected by suction from above, diluted in distilled water and centrifuged at $170000 \mathrm{~g}$. The final pellet from each band was resuspended in a small volume of distilled water and stored at $-70^{\circ} \mathrm{C}$.

Inclusion bodies containing insoluble proteins were obtained by low speed centrifugation $\left(2000 \mathrm{~g}, 10 \mathrm{~min}\right.$ at $\left.4{ }^{\circ} \mathrm{C}\right)$ of whole-cell lysates (prepared by French pressing) and three subsequent washes of the pellet with $50 \mathrm{mM}$ Tris $/ \mathrm{HCl}, \mathrm{pH} 7 \cdot 5-8 \cdot 0$, containing $100 \mathrm{mM} \mathrm{NaCl}$ and $2 \mathrm{mM}$ EDTA (Studier et al., 1990). The final pellet containing the inclusion bodies was resuspended in a small volume of the same buffer.

Preparation of porcine transferrin subfragments and affinity columns. Porcine transferrin $\mathrm{C}$ - and $\mathrm{N}$-lobes were prepared by cleavage of intact iron-loaded porcine transferrin $\left(20 \mathrm{mg} \mathrm{ml}^{-1}\right)$ in $50 \mathrm{mM}$ Tris $/ \mathrm{HCl}$ buffer, $\mathrm{pH} 7 \cdot 5$, with trypsin $\left(0.4 \mathrm{mg} \mathrm{ml}^{-1}\right)$ for $6 \mathrm{~h}$ at room temperature. Trypsin was inactivated by passing the incubation mixture through a soybean trypsin inhibitor/ Sepharose affinity column followed by addition of PMSF to $0.8 \mathrm{mg} \mathrm{ml}^{-1}$. The individual lobes were subsequently isolated by a combination of gel exclusion chromatography on a Sephadex G-100 column and affinity-chromatography using ConASepharose, taking advantage of the presence of $\mathrm{N}$-linked oligosaccharide on the C-lobe. Trypsin inhibitor and the purified $\mathrm{C}$ - and N-lobes were coupled to $\mathrm{CNBr}$-Sepharose $4 \mathrm{~B}$ (Pharmacia) following the manufacturer's protocol.

Affinity-chromatography was performed as described by Irwin et al. (1993). Briefly, native or recombinant Tbp1 or Tbp2 were solubilized in a sarkosyl/EDTA solution from various cell fractions (containing $0.5-1.0 \mathrm{mg}$ protein) and added to a suspension containing pTf-Sepharose $4 \mathrm{~B}$ or to the resin conjugated to the $\mathrm{C}$ - or N-lobe of pTf. The affinity resin was subsequently washed and bound proteins were eluted by application of SDS-PAGE sample buffer. After isolation, samples were run on SDS-PAGE, electroblotted, exposed to anti-Tbp1 or anti-Tbp2 antisera, HRP-conjugated goat antirabbit antiserum and developed with a chromogen (tetramethylbenzidine, Sigma) $/ \mathrm{H}_{2} \mathrm{O}_{2}$ mixture as described below.

Assays of the cell fractions Samples of intact cells or the various cell fractions were assayed for binding of porcine transferrin or specific antibody after spotting samples $(10 \mu \mathrm{g} / 5$ $\mu \mathrm{l})$ onto HA paper, drying and blocking with TBS buffer 
(50 mM Tris/ $\mathrm{HCl}, 100 \mathrm{mM} \mathrm{NaCl}, \mathrm{pH} \mathrm{7.5)} \mathrm{containing} 0.5 \%$ skimmed milk (blocking buffer). Alternatively, samples $(10 \mu \mathrm{g}$ protein) were subjected to SDS-PAGE, electroblotted onto polyvinylidene difluoride (PVDF) membrane and exposed to blocking solution. The membranes were then exposed to blocking buffer containing $1 \mu \mathrm{g} \mathrm{ml}^{-1}$ HRP-pTf or a $1 / 500$ to $1 / 40000$ dilution of the anti-Tbp1 or anti-Tbp2 antisera and incubated for $1 \mathrm{~h}$ at $37^{\circ} \mathrm{C}$. The binding solutions were removed, the membranes washed with TBS buffer and either developed with a substrate solution containing $50 \mu \mathrm{g}$ tetramethylbenzidine $\mathrm{ml}^{-1}$ and $0.02 \%(\mathrm{v} / \mathrm{v}) \mathrm{H}_{2} \mathrm{O}_{2}$ (HRP-pTf-treated membrane) or first exposed to a $1 / 3000$ dilution of HRPconjugated goat antirabbit IgG (Sigma) prior to development.

$\mathbf{N}$-terminal amino acid sequence analysis and sequence aligment. Samples of affinity-purified Tbp1 and Tbp2 as well as purified pTf N-lobe and C-lobe were subjected to SDS-PAGE, electroblotted onto PVDF (Immobilon-P, Millipore) membrane, briefly stained with Coomassie Blue, and strips containing the individual protein bands were cut from the membrane. Nterminal amino acid sequence analysis was performed by Sandy Kieland at the University of Victoria, BC, Canada.

Sequence aligment of the $A$. pleuropneumoniae Tbp1 proteins and comparison to other species $\mathrm{Tbp} 1 \mathrm{~s}$ was done manually using the DNASIS Mac V2.0 program.

Photograph processing. The gel and blots appearing in the Figs 4, 5 and 6 have been scanned using a Hewlett Packard Scan Jet IIp scanner.

\section{RESULTS}

\section{Cloning of the tbpA and tbpB genes from A. pleuropneumoniae}

Antiserum prepared against purified receptor complex (Tbp1 and Tbp2) from $A$. pleuropneumoniae strain $\mathrm{h} 49$, was used to screen a recombinant phage genebank containing chromosomal DNA from the same strain. After identifying and plaque-purifying potentially positive recombinant phage, the products encoded by the cloned genes were analysed by electrophoresis and electroblotting of phage-infected cells followed by reaction with anti-receptor antiserum. Two recombinant phage were selected for the in vivo excision procedure (Short et al., 1988), and the resulting recombinant pBluescriptII $\mathrm{SK}(+)$ plasmids, $\mathrm{pBAPT} 1$ and $\mathrm{pBAPT} 2$, were compared by restriction endonuclease digestion analysis (Fig. 1). The products encoded by the recombinant plasmids were analysed after IPTG-induction of plasmid-containing cells and compared to the recombinant phage-encoded proteins by Western blot analysis with antisera against Tbp1, Tbp2, and the receptor complex.

The linear maps of several recombinant pBluescriptII $\mathrm{SK}(+)$ plasmids containing inserts encoding proteins reactive with anti-receptor antibodies are illustrated in Fig. 1. Strains carrying the pBAPT1 plasmid, which contains a $9 \mathrm{~kb}$ insert, expressed two protein products of approximately 100000 and $58000 \mathrm{kDa}$ which were reactive with anti-Tbp1 and anti-Tbp2 antisera, respectively. Plasmid pBAPT2 contained a $3.0 \mathrm{~kb}$ insert that encoded a $58 \mathrm{kDa}$ protein reactive with anti-Tbp2 antisera that co-migrated with the Tbp2 protein expressed by pBAPT1. The observed overlap in the restriction maps of

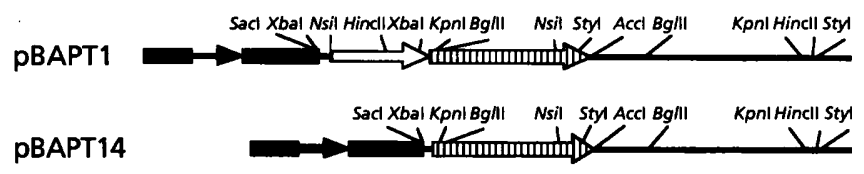

PBAPT11 SacI Nsil Hincll Xbal Konl Bghl Nsil Styl

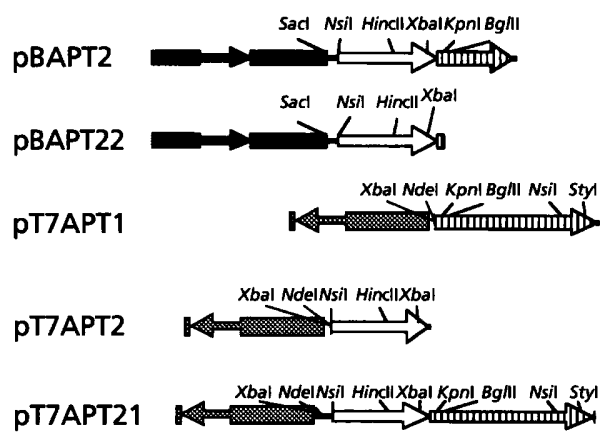

Fig. 1. Restriction maps of recombinant plasmids. Black solid bars represent the pBluescript vector in the PBAPT1, PBAPT14, PBAPT11, PBAPT2, and PBAPT22 plasmids. Stippled bars represent the pT7-7 vector in the pT7APT1, pT7APT2, and pT7APT21 plasmids. Enclosed solid and stippled arrows in the vectors indicate the location and orientation of the $\beta$-lactamase gene encoding ampicillin resistance. Solid lines represent regions of the insert DNA not encoding the Tbp proteins. Clear arrows represent the tbpB region and the arrows with vertical lines represent the tbpA region. The direction of the arrows indicate the direction of transcription of the indicated genes.

the inserts in these two plasmids enabled rough localization of the receptor genes and selective subcloning enabled more refined localization. The plasmid pBAPT11 was derived from pBAPT1 by digestion with AccI, blunting the resulting ends by Klenow treatment, and religation of the $7.6 \mathrm{~kb}$ fragment. Strains carrying this plasmid produced both intact Tbp1 and Tbp2. Plasmid pBAPT22, constructed by removal of a $1.2 \mathrm{~kb} K p n \mathrm{I}$ insert from $\mathrm{pBAPT} 2$, expressed intact recombinant Tbp2 protein. Plasmid pBAPT14, constructed by removing a $1.7 \mathrm{~kb}$ $X b a$ I fragment from $\mathrm{pBAPT} 1$, expressed recombinant Tbp1 protein but not Tbp2. Comparison of the products of these plasmids allowed tentative localization of the $t b p A$ (encoding Tbp1) and $t b p B$ (encoding Tbp2) genes.

Determination of the nucleotide sequence of the $t b p B / A$ region from strain h49 (see below) enabled us to design oligonucleotide primers based on the $5^{\prime}$ and $3^{\prime}$ ends of the genes (Table 1) for PCR amplification of the intact genes from chromosomal DNA. These oligonucleotide primers were designed to introduce an NdeI site at the start codon of the gene and a HindIII site after the stop codon to facilitate cloning into the expression vector pT7-7. In PCR reactions the $t b p A$ gene (primers 042 and 043 ), the $t b p B$ gene (primers 044 and 045 ) and the $t b p B / A$ region (primers 044 and 043) were amplified using chromosomal DNA from strain h49 as template. When the serotype 1 strain h171 chromosomal DNA was used as template, only the $t b p A$ gene (primers 042 and 043 ) and the $t b p B / A$ 
Table 1. Oligonucleotides used for PCR amplification

\begin{tabular}{|lll|}
\hline Primer & \multicolumn{1}{c|}{ Sequence* } & Description \\
\hline 042 & CATATGAAAAATAAATTAAATCTG & $t b p A 5^{\prime}$ end \\
043 & AAGCTTGAAACTAAGGTACTCTAA(ATTA) & $t b p A 3^{\prime}$ end \\
044 & CATATGCATTTTAAACTTAATCCC & $t b p B 5^{\prime}$ end \\
045 & AAGCTTGCACCTTCCTTATTATTT & $t b p B 3^{\prime}$ end \\
\hline
\end{tabular}

*Nucleotides encoding the start and stop codons of the tbp genes are underlined. Nucleotides corresponding to the NdeI and HindIII sites are indicated in bold. Nucleotides enclosed in brackets are not part of the oligonucleotide primer but correspond to the adjacent sequence in the chromosomal DNA.

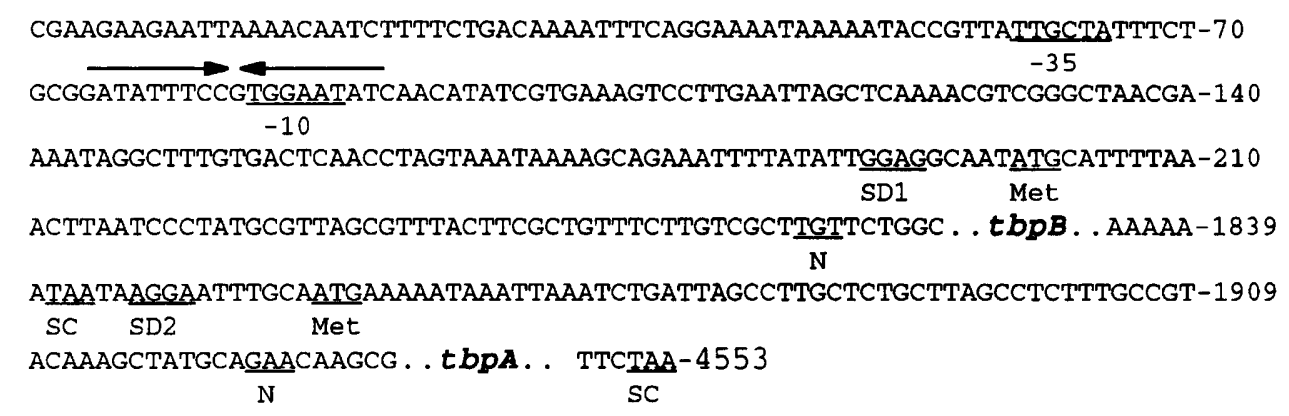

\begin{abstract}
Fig. 2. DNA sequence of the non-coding regions in the tbp operon. The nucleotide sequence of flanking regions of the tbp genes determined from the inserts in plasmids PBAPT1 and pBAPT2 is indicated by capital letters. The nucleotide sequences of the coding regions for the $t b p B$ and $t b p A$ genes have been omitted and replaced by a series of dots and the respective gene name. The putative -10 and -35 promoter sequences are underlined. Abbreviations and symbols for other sequences are: arrows in opposite direction, region with homology to Fur binding site; SD1 and SD2, putative RBSs; Met, initiation codons; N, N-terminus of the mature proteins; SC, stop codons.
\end{abstract}

region (primers 044 and 043 ) were readily amplified. The PCR products were initially cloned into the SmaI site of the pBluescriptII $\mathrm{SK}(+)$ plasmid. The NdeI/HindIII fragments were subsequently inserted into the pT7-7 expression vector which provides an appropriately spaced RBS downstream from the T7 promoter. Plasmids pT7APT1 and pT7APT2 containing the $t b p A$ and $t b p B$ genes from strain h49 (Fig. 1) were obtained in this fashion. Due to some initial difficulties in expressing Tbp1 and Tbp2 from the PCR product for the intact $t b p B / A$ region, an EcoRI/XboI fragment obtained from pBAPT11 was subcloned into the compatible sites EcoRI/Sall in pT7-7 to produce pT7APT21 (Fig. 1).

\section{DNA sequence analysis and predicted protein sequences}

DNA sequence analysis of the region from strain h49 immediately upstream of the assigned translation initiation codon for $t b p B$ revealed a putative tetrameric sequence with a good match to the consensus RBS (Gold, 1988) (SD1, Fig. 2). A search for hexameric sequences with significant homology to the consensus -10 (TATAAT) and -35 (TTGACA) sequences with appropriate spacing $(17 \pm 1 \mathrm{bp})$ yielded a putative promoter site $(-35,-10$, Fig. 2). A search for homology to the consensus E. coli Fur operator site (GATAATGATAATCATTATC) (Calderwood \& Mekalanos, 1988) identified one putative Fur box with more than $50 \%$ identity to the consensus sequence and the evident dyad symmetry that is characteristic of these operator sites (arrows in opposite direction, Fig. 2). However, a gap in the proposed Fur box makes the dyad symmetry imperfect, which at present we can only explain as a possible artefact due to cloning in E. coli.

There was a short (13 bp) intercistronic region between the $t b p B$ and $t b p A$ coding regions containing a sequence with weak homology to the consensus RBS immediately upstream of the translation initiation of the $t b p A$ gene (SD2, Fig. 2).

Nucleotide sequence analysis of the $t b p B$ region in pBAPT2 revealed an ORF of 1641 bp encoding a protein with a predicted molecular mass of $59818 \mathrm{Da}$ which correlates with the estimated molecular mass of 58000 on SDS-PAGE analysis. The ORF was confirmed by an inframe fusion of a Bam HI fragment containing the $p h o A$ gene into the $B g / \mathrm{II}$ site that resulted in alkaline phosphatase positive transformants. Only five nucleotide differences were detected between this sequence and the previously published sequence of the $t b p B(t f b A)$ gene from serotype 7 strain AP205 (Gerlach et al., 1992b), resulting in the following amino acid substitutions: $\mathrm{D}$ for $\mathrm{N}_{290}, \mathrm{P}$ for $\mathrm{A}_{454}$, and $\mathrm{A}$ for $\mathrm{E}_{470}$. Similarly, the nucleotide sequence of the $t b p B$ gene from strain h171 (GenBank accession no. U16019) was almost identical to the $t b p B$ 


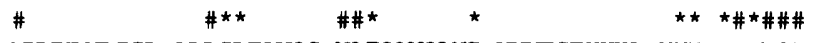

Aph49 MKNKLNLISL ALLSLFAVQS YAEOAVOLND VYVTGTKKKA HKKENEVTGL 50

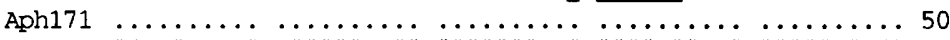

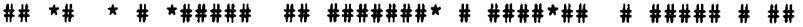

Aph49 GKVVKTPDSL SKEQVLGMRD LTRYDPGISV VEQGRGATTG YSIRGVDRNR 100

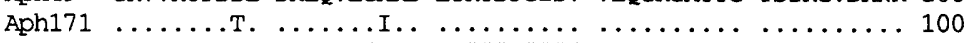

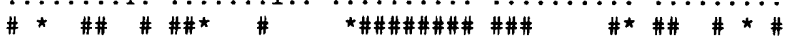

Aph49 VGLALDGLPQ IQSYVSQYSR SSSGAINEIE YENLRSIQIS KGASSSEFGS 150

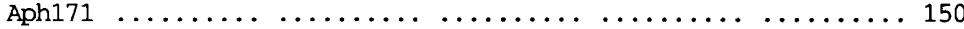

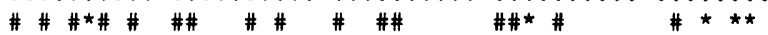

Aph49 GSLGGSVQFR TKEVSDIIKP GQSWGLDTKS AYSSKNQQWL NSLAFAGTHN 200

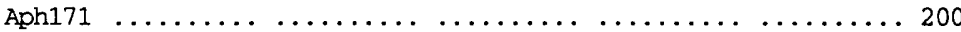

$\# \# \# \# \# \# \#$ \#\#\# *

Aph49 GFDALVIYTH RDGKETKAHK DAESRSKSIQ RVDLADNNPQ GSNWFKVKND 250

Aph171 $\ldots \ldots \ldots \ldots \ldots \ldots \ldots \ldots \ldots$. . . . . . . GVET. ELD T. . RYTATTN 250

Aph49 --.

Aph171 NQHTYGWFLI KDECPTLDCT PKQMARVTKD TPSFRSYPEY TPEEKQA.EN 300

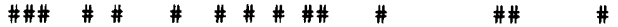

Aph49 QKYITEQLSA KEYTGEERAL PDPVKYKSDS WLVKLGYSLS PKHYVAGVYE 318

Aph171 ..H...R.N. QD...Y... ...L............TF. ...... . . 350

$\# \# \# \# \# \# \#$ *

Aph49 HSKQRYDTRD MTYPAYWQLS DL-KNGDKWY PMNNAKGLYR DNALDGVAID 367

Aph171 $\ldots \ldots \ldots \ldots \ldots$.....P. ..LRT.RN. . ..............400

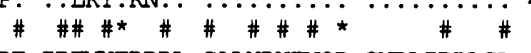

Aph49 YFTEDGVKSS KGLRWAKARF IDEWHTRDRL GALYRYTNQD GNRLIDRLSL 417

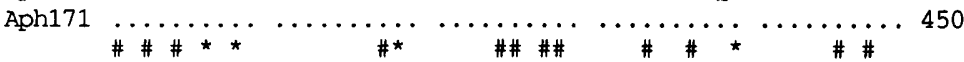

Aph49 SFDQQKINLS TRLRENNCSE YPTIDKNCRA TLDKLWSSTK NEQSSYEEKH 467

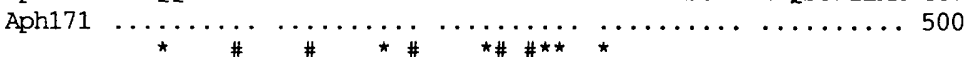

Aph49 DTIQLSLDKT VQTGLGKHQL NMLLGSDRFN STLKRHEILS EFSVGTWHRI 517

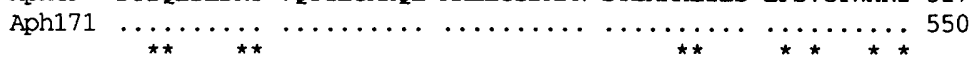

Aph49 RGNGYKDTPY IYELKDQAIY SKNECDYSGT IAGRADCATS KIKGHNHYIA 567

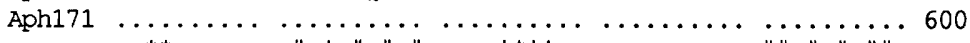

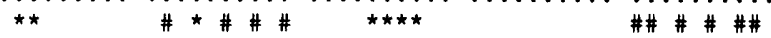

Aph49 LRDNFAITKY LDIGLGYRFD KHKFRSTHRW ANQGDYKNSA WNIGIVAKPT 617

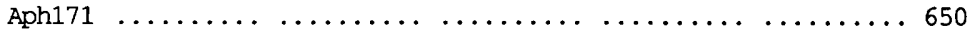

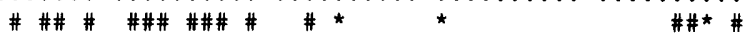

Aph49 SFLSLSYRAS SGFRVPSFQE LFGLRYDGAM KGSSDAYQKT EKLSPEKSLN 667

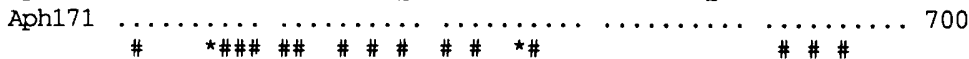

Aph49 QEVAATFKGD FGVVEVSYFK NDYKQLIAPA ERMHQTQSMI NYFNVQDIKL 717

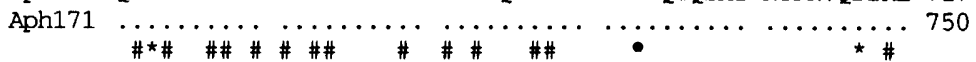

Aph49 DGINLIGKLD WNGVFDKIPE GIYTTLAYSK MRVKEVKNYQ GYMNIRSPLL 767

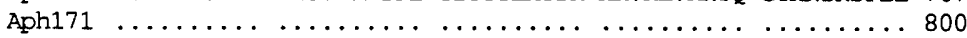

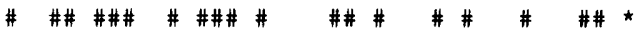

Aph49 DTIQPARYVV GVGYDQPDEK WGVNLTMTHS SGKNPNELRG NEQVGFANYE 817

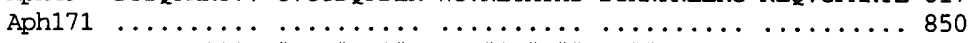

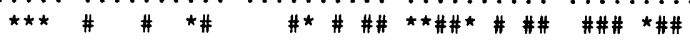

Aph49 RTATKKRTRS WHTFDLTGYI TPWKHTTVRA GVYNLMNYRY TTWESVRQSS 867

Aph171 .................................... 900

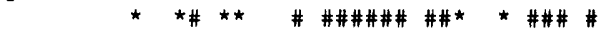

Aph49 LNAIHQHTNV KDYARYAAPG RNYVVSFEMK F 1998

Aph171 $\ldots \ldots \ldots \ldots \ldots \ldots \ldots \ldots \ldots \ldots \ldots \ldots$
Fig. 3. Concise representation of the alignment of the predicted amino acid sequences of the Tbp1s from $A$. pleuropneumoniae strains $\mathrm{h} 49$ and $\mathrm{h} 171$ and comparison with Tbp1s and Lbp from Neisseria spp. The complete amino acid sequence for strain h49 is illustrated in capital letters with dashes to mark two gaps (at lines 268 and 367 ) introduced to align the two $A$. pleuropneumoniae sequences. The underlined amino acids are those obtained from $\mathrm{N}$-terminal amino acid sequence analysis of the $A$. pleuropneumoniae Tbp1 mature protein. The area of double underlining corresponds to the region homologous to the $E$. coli 'TonB box'. For strain $\mathrm{h} 171 \mathrm{a}$ dot is used to indicate residues identical to those in strain h49; mismatched amino acids are given. Asterisks above residues in h49 indicate identity with the Tbp1s from $N$. meningitidis and $N$. gonorrhoeae and \# indicates identity with these Tbp1s and also with the Lbp from N. meningitidis. $(t f b A)$ gene (accession no. M85274) from the serotype 1 strain reported previously (Gerlach et al., 1992b).

Nucleotide sequence analysis of the $\operatorname{tbp} A$ region in pBAPT1 revealed an ORF of 2694 bp encoding a protein (Fig. 3) with a predicted molecular mass of $102186 \mathrm{Da}$ which correlates with the estimated molecular mass of $105000 \mathrm{Da}$ on SDS-PAGE analysis. The putative signal peptidase cleavage site at residue 23 was confirmed by comparison with the determined $\mathrm{N}$-terminal amino acid sequence of the purified Tbp1 protein (Fig. 3, underlined). Additional support for assignment of the ORF was obtained by an in-frame fusion of an $\mathrm{XbaI}$ fragment containing the $p b o A$ gene into the $X b a \mathrm{I}$ site that resulted in $\mathrm{PhoA}^{+}$transformants.

The predicted protein sequences of the A.pleuropneumoniae Tbp1 proteins from strains h49 and h171 were aligned with the predicted sequences of the Tbp1 from $N$. meningitidis (Legrain et al., 1993), $N$. gonorrrboeae (Cornelissen et al., 1992), and Lbp from N. meningitidis (Pettersson et al., 1993). Relevant aspects of that aligment are concisely presented in Fig. 3 . The two $A$. pleuropneumoniae $\mathrm{Tbp} 1 \mathrm{~s}$ were nearly identical except for a stretch of amino acids about one-quarter to one-third of the way into the protein (starting at residue 227 in Aph171 
Fig. 4. Expression of the $A$. pleuropneumoniae tbpA and tbp $B$ genes in $E$. coli. Cells of strain BL21 containing plasmid pT7APT21 (a-c, lane 2), pT7APT1 (a-c, lane 3 ) or PT7APT2 (a-c, lane 4) were harvested $2 \mathrm{~h}$ after infection with CE6 phage. Aliquots of the resuspended cell pellet were applied to duplicate SDSpolyacrylamide gels and, after electrophoresis, the resulting gels were either stained with Coomassie Blue (a) or electroblotted and reacted with antisera against Tbp1 (b) or Tbp2 (c). A control preparation of native transferrin receptor isolated from $A$. pleuropneumoniae strain h49 is present in lane 1. Molecular masses of native h49 Tbp 1 (top) and Tbp2 (bottom) are indicated on the left.

Tbp1). There was a considerable degree of identity with the Neisseria Tbp1s and Lbp, particularly near the $\mathrm{N}$ - and C-terminal ends of the proteins. Some of the clusters of identical amino acids were localized at, or near to, seven regions of homology with TonB-dependent receptors identified previously (Cornelissen et al., 1992). However, there was little identity in domain 1 , which includes the putative 'TonB box' (double-underlined residues in Fig. $3)$, the region which has been implicated in interaction with TonB (Bell et al., 1990).

\section{Expression of the tbp genes and localization of the recombinant Tbp proteins}

To investigate the heterologous production of the receptor proteins and their localization, the $t b p B$ and $t b p A$ genes were introduced into a $\mathrm{T} 7$ expression system using E. coli strain BL21 as a host. In this system the level of expression was sufficient for detection of Tbp1 from BL21/pT7APT21 and BL21/pT7APT1 (Fig. 4a, lanes 2 and 3 , respectively) and $\mathrm{Tbp} 2$ from strains BL21/pT7APT21 and BL21/pT7APT2 (Fig. 4a, lanes 2 and 4 , respectively) in Coomassie Blue-stained SDSPAGE gels of whole cells. The identity of the recombinant proteins was confirmed by reactivity with polyclonal antisera against the respective proteins (Fig. $4 \mathrm{~b}, \mathrm{c}$ ). The majority of the immunoreactive products were of comparable size to the native receptor proteins (lane 1).

To determine the relative surface exposure of the recombinant receptor proteins, intact and lysed cells were reacted with specific antibody directed against the individual receptor proteins (data not shown). Recombinant Tbp1 protein expressed by BL21/pT7APT1 was present at the bacterial surface since reactivity with anti-Tbp1 was not enhanced upon cell lysis. Similarly, the Tbp2 protein expressed by BL21/pT7APT2 was readily detected by anti-Tbp2 antiserum in intact cells and the reactivity was not markedly altered after disruption of the cells by sonication.

Since recombinant receptor proteins were not observed in the cytosolic/periplasmic fractions in preliminary experi- ments, subsequent analysis was focussed on fractions representing inclusion bodies/insoluble protein, IMs and OMs. When sucrose density gradients were used for isolation of IM and OM fractions, a third band was observed in preparations obtained from strains expressing recombinant Tbp2 (BL21/pT7APT2 or BL21/pT7APT21). This band was found near the bottom of the gradient (interface between $64 \%$ and $70 \%$ ), lacked NADH oxidase activity, and had comparable levels of endotoxin (LPS) as the normal OM fraction. SDS-PAGE analysis showed a typical $O M$ protein pattern with an additional band corresponding to $\mathrm{Tbp} 2$. Based on these characteristics this bottom band is subsequently referred to as the modified OM fraction, and the presence of Tbp2 suggests that this protein is being properly processed to the OM.

Aliquots from various fractions were subjected to SDSPAGE before (Fig. 5, top) and after (Fig. 5, bottom) affinity-isolation. Following Western blotting the bound PVDF membranes were exposed to anti-Tbp1 antiserum (Fig. 5a) or anti-Tbp2 antiserum (Fig. 5b). Recombinant Tbp1 expressed in BL21/pT7APT1 whole cells (Fig. 5a, top, lane 2) was present in inclusion bodies (Fig. 5a, top, lane 4) and in the normal OM fraction (Fig. 5a, top, lane 6) but was absent from the IM fraction (Fig. 5a, top, lane 5). The amount of Tbp1 detected in the lysate, inclusion bodies and OM (Fig. 5a, lanes 3, 4 and 6) was unexpectedly low relative to that observed in whole cells (Fig. 5a, top, lane 2), suggesting that proteolysis of 'Tbp1 was occurring even in the presence of the protease inhibitor 4-(2aminoethyl)-benzenesulfonylfluoride- $\mathrm{HCl}$. The appearance of a lower-molecular-mass protein detected with anti-Tbp1 antiserum (Fig. 5a, top, lane 6) is consistent with this proposal. Recombinant Tbp2 expressed in BL21/pT7APT2 (Fig. 5b, top, lanes 2-7) was present predominantly in inclusion bodies (Fig. 5b, top, lane 4), and in the modified OM fraction (Fig. 5b, top, lane 7), was not detected in the IM fraction (Fig. 5b, top, lane 5) and was barely detectable in the normal OM fraction (Fig. 5b, top, lane 6). The fractionation of recombinant Tbp1 and Tbp2 from strain BL21/pT7APT21 was essentially identical to that of the individually expressed proteins illustrated in Fig. 5. Even though the recombinant Tbp2 
(a)

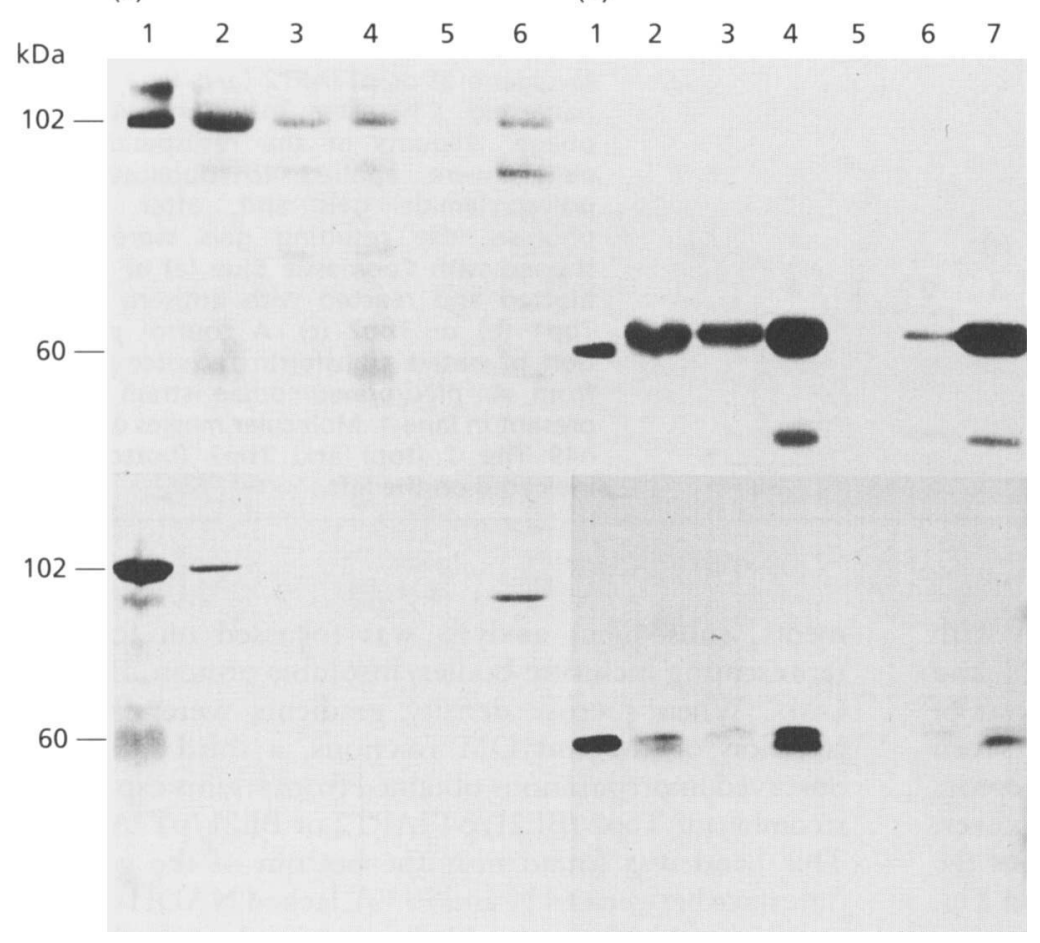

Fig. 5. Localization and affinity-isolation of A. pleuropneumoniae recombinant Tbp1 and Tbp2. Western blots were obtained following SDS-PAGE and reacted with (a) anti-Tbp1 antiserum or (b) anti-Tbp2 antiserum, followed by exposure to HRPantirabbit IgG and final development with a chromogen $/ \mathrm{H}_{2} \mathrm{O}_{2}$ mixture as described in Methods. Top: direct Western blots of aliquots $(10 \mu \mathrm{g}$ protein) of various cell fractions from strain BL21/pT7APT1 (a, lanes 2-6) or strain BL21/pT7APT2 (b, lanes 2-7) which were obtained from cells harvested 2 $h$ post-infection with CE6 phage as described in Methods. Bottom: Western blots following affinity-isolation of Tbp1 and Tbp2 recombinant proteins. Various preparations obtained from $E$. coli BL21/ pT7APT1 (a, lanes 2-6) or BL21/pT7APT2 (b, lanes 2-7) were affinity-chromatographed and assayed as described in Methods. Lanes: 1, purified native receptor complex from $A$. pleuropneumoniae (h49); 2, whole cells; 3 , lysed whole cells; 4, insoluble protein/inclusion body fraction; 5, IM fraction; 6, normal OM fraction; 7, modified OM fraction. Note that lane 7 is missing in BL21/pT7APT1 (a, top and bottom) because this strain did not produce a modified OM in sucrose density gradient. Molecular masses of porcine Tbp1 and Tbp2 are indicated on the left.
(Fig. 5a, top) appeared to be more stable than the recombinant Tbp1 (Fig. 5b, top), some anti-Tbp2 immunoreactive proteolytic products also appeared below the normal molecular mass of $\mathrm{Tbp} 2$. The identity of these putative proteolytic products was confirmed by the failure to eliminate immunoreactivity by pre-incubation of the antisera with BL21 lysate.

To assess the binding properties of the recombinant ' $T b p s$, the various fractions were solubilized with a Sarkosyl/EDTA mixture and the resulting extracts were applied to a porcine transferrin-Sepharose affinity resin (Fig. 5, bottom). Tbp1 was isolated from extracts obtained from control $A$. pleuropneumoniae crude membranes (Fig. $5 \mathrm{a}$, bottom, lane 1) and from the BL21/pT7APT1 cells (Fig. 5a, bottom, lane 2). A slightly lower-molecular-mass protein reactive with anti-Tbp1 antiserum was isolated from the OM fraction (Fig. 5a, bottom, lane 6). This is likely a proteolytic derivative that is produced due to the incomplete inhibition of intrinsic proteases during the affinity procedure. No detectable protein was isolated from the IM fraction (Fig. 5a, bottom, lane 5) or from the 'insoluble protein' fraction (Fig. 5a, bottom, lane 4), in spite of the presence of recombinant Tbp1 in this fraction (Fig. 5a, top, lane 4).

In contrast to the results obtained with Tbp1, affinityisolation of $\mathrm{Tbp} 2$ from the various fractions (Fig. 5b, bottom) was a reflection of the relative content of Tbp2 present (Fig. 5b, top). Thus, Tbp2 was isolated from the control $A$. pleuropneumoniae crude membranes (Fig. 5b, bottom, lane 1), the BL21/pT7APT2 cells (Fig. 5b, bottom, lane 2), the 'insoluble protein' fraction (Fig. 5b, bottom, lane 4) and the modified OM fraction (Fig. 5b, bottom, lane 7) obtained from those cells.

\section{Characterization of the recombinant Tbp proteins}

Purified preparations of intact pTf and the proteolytically derived N-lobe and C-lobe fragments were coupled to Sepharose $4 \mathrm{~B}$ and used in affinity experiments to evaluate their ability to bind Tbp1 and Tbp2. The identity of the purified C-lobe was confirmed by reactivity with ConA after SDS-PAGE and electroblotting, and was further substantiated by $\mathrm{N}$-terminal amino acid sequence analysis and comparison with the published sequence of the porcine transferrin gene (Baldwin \& Weinstock, 1988). The N-terminal amino acid sequence NECKKVRWCA localized the primary cleavage site to residue 341 which is in the predicted inter-domain bridge between the C-and $\mathrm{N}$-lobes. Additional sequence LLEACTHFS, APGRE and HVTD corresponding to cleavage at residues 678 , 510 and 620 could be identified in the C-lobe preparation and were associated with a major $(44 \mathrm{kDa})$ band during SDS-PAGE even if the samples were treated with reducing agent. However, the appropriate peptides were released upon boiling the samples in the presence of reducing agent.

As shown in Fig. 6, affinity-isolation using p'Tf-Sepharose isolated $\mathrm{Tbp} 1$ and $\mathrm{Tbp} 2$ from A. pleuropneumoniae membranes (Fig. 6a, lane 1), and from membranes containing both recombinant $\mathrm{Tbp} 1$ and $\mathrm{Tbp} 2$ (Fig. 6b, 
(a)

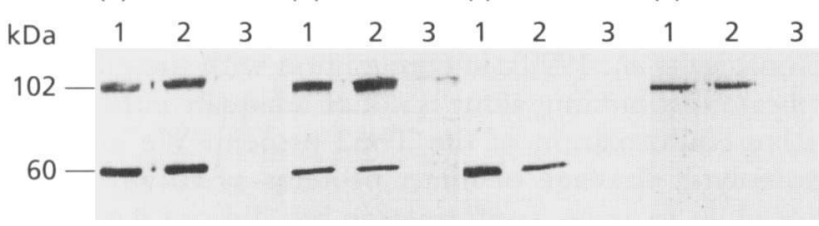

Fig. 6. Affinity-isolation of Tbp1 and Tbp2 with porcine transferrin fragments. Samples (1 mg protein) of crude total membranes from $A$. pleuropneumoniae strain h49 (a), E. coli SURE/PBAPT1 (b), $E$. coli SURE/pBAPT22 (c), and $E$. coli SURE/PBAPT14 (d) were affinity-chromatographed using either pTf (a-d, lane 1), pTf C-lobe (a-d, lane 2) or pTf N-lobe (a-d, lane 3) conjugated to Sepharose $4 B$ as described in Methods. The final electroblots were exposed to a dilution of anti-Tbp1 and anti-Tbp2 sera, followed by exposure to HRP-antirabbit IgG and final development with chromogen $/ \mathrm{H}_{2} \mathrm{O}_{2}$ mixture as described in Methods.

lane 1). In addition, pTf-Sepharose bound individual recombinant Tbp2 (Fig. 6c, lane 1) or recombinant Tbp1 (Fig. 6d, lane 1). Similarly, the C-lobe affinity resin was capable of isolating both native and recombinant Tbp1 and Tbp2 proteins (Fig. 6a-d, lane 2). In contrast, receptor proteins were not readily detected when affinity experiments were performed with the affinity resin containing coupled N-lobe fragment (Fig. 6a-d, lane 3). We obtained essentially the same results when an affinity method using biotinylated preparations of the proteins immobilized with streptavidin-agarose was used. An excess of soluble $\mathrm{pTf}$, but not other transferrins, inhibited the isolation of native and recombinant Tbps (data not shown), but when the coupled ligands were converted to the apo forms, there was a noticeable reduction in the amount of Tbp2, but not Tbp1, isolated. Recombinant Tbp1, recombinant Tbp2, and the native receptor from A. pleuropneumoniae could be affinity-isolated with porcine transferrin-Sepharose but not with human or bovine transferrin conjugated to the resin (data not shown), indicating that the recombinant proteins had the same specificity for porcine transferrin ( $\mathrm{pTf}$ ) as the native receptor.

In accordance with the results obtained with specific antibody, binding of porcine transferrin was observed in intact cells expressing recombinant Tbp1 and no increase in binding was observed upon cell lysis (data not shown). In contrast, intact cells expressing recombinant $\mathrm{Tbp} 2$, which was accessible to antibody on the surface, did not demonstrate any obvious binding of labelled porcine transferrin before or after disruption of BL21/pT7APT2 cells by sonication.

\section{DISCUSSION}

The cloning and sequence analysis of the $\operatorname{tbp} B(t f b A)$ genes, encoding only Tbp2, from two strains of $A$. pleuropneumoniae was reported by Gerlach et al. (1992b) and a considerable amount of sequence upstream and downstream of the coding sequence was included for one of the strains. However, these authors did not identify the downstream region as a portion of the $\operatorname{tbp} A$ gene encoding Tbp1 nor did they comment on any putative regulatory regions upstream of the $t b p B$ gene. In this study, we were able to clone the entire $t b p$ region in a single fragment and demonstrate that it encoded both Tbp2 and Tbp1.

The present results suggest that the $A$. pleuropneumoniae $\operatorname{tbp} B$ gene precedes the $\operatorname{tbp} A$ gene in an operon arrangement, which is analogous to what is observed in $N$. meningitidis (Legrain et al., 1993) and N. gonorrboeae (Anderson et al., 1994). The absence of obvious promoter sequences in the $85 \mathrm{bp}$ intercistronic region upstream of the Neisseria tbp $A$ gene (Legrain et al., 1993; Cornelissen et al., 1992) suggested that the two genes might be transcribed from a single promoter; this was confirmed by elimination of $t b p A$ expression upon insertional mutagenesis in the $\operatorname{tbp} B$ gene with an $\Omega$ fragment (Anderson et al., 1994). The short $13 \mathrm{bp}$ intercistronic region between the tbp genes in $A$. pleuropneumoniae strongly suggests that, similarly to Neisseria spp., the two genes are probably transcribed from a single promoter. However, the operon arrangement of the tbp genes in $A$. pleuropneumoniae will have to be verified by direct experimentation.

In the presence of ferrous ions, Fur, a ferrous-ion-binding repressor protein, binds to a specific sequence located near to the promoter, termed the Fur box, thus blocking transcription (Litwin \& Calderwood, 1993). It is likely that $t b p$ genes are regulated by Fur since putative Fur boxes have been identified upstream of the $t b p B$ gene in N. meningitidis (Legrain et al., 1993), N. gonorrboeae (Anderson et al., 1994), H. influenzae (Gray-Owen et al., $1995)$ and, based on the results of the present study, $A$. pleuropneumoniae. However, direct experimental evidence is needed to support this proposal. The observation that expression of transferrin-binding by $H$. influenzae requires a gene encoding $\mathrm{TbpR}$, a protein homologous to OxyR (Maciver \& Hansen, 1994), indicates that regulation of the $t b p$ genes is likely influenced by environmental factors other than iron.

The predicted Tbp1 sequences of the serotype 1 and serotype 7 strains of $A$. pleuropneumoniae had a high degree of identity, demonstrating that there is much less variation in their sequences than in the Tbp2 sequences (Gerlach et al., 1992b), which is reminiscent of the situation with $N$. meningitidis (Legrain et al., 1993). This may be a reflection of their relative surface accessibility and the resulting selective pressures for antigenic variation. Upon inspection of the Tbp1 alignment it is evident that most of the variation is in a region in the Tbp1 of $A$. pleuropneumoniae where there is also little homology to the Neisseria Tbp1s or Lbp. It is interesting to note that this region also aligned with a large surface loop in the E. coli siderophore receptor, FepA, which is proposed to act as a 'gate' (Rutz et al., 1992). The variability observed in this region is likely due to antigenic variation and is thus consistent with the proposed surface exposure.

The $A$. pleuropneumoniae $\mathrm{Tbp} 1 \mathrm{~s}$ are very basic proteins (pI 
9.5 and 9.4), a property they share with Tbp1s from $N$. gonorrboeae (Cornelissen et al., 1992) and N. meningitidis ( $\mathrm{pI}$ $9 \cdot 2$ and 9.3)(Legrain et al., 1993), and which is in contrast to the acidic E. coli tonB-dependent OM proteins. The basic nature of these proteins may be related to the function of Tbp1 rather than being due to a general feature shared by other surface proteins in a given species (Cornelissen et al., 1992), particularly considering that the Tbp2s of $A$. pleuropneumoniae (pI 6.4 and 6.7) and $N$. meningitidis (pI 6.3 and 6.2)(Legrain et al., 1993) are nearly neutral.

In agreement with a previous study by Gerlach et al. (1992a), we observed that during high-level expression a significant proportion of the Tbp2 was present in an insoluble protein fraction (inclusion bodies). In addition, we observed that a significant amount of the Tbp2 was present in a novel OM band that appeared in sucrose density gradients concomitant with over-expression of Tbp2, but not of Tbp1. Lipoproteins, like Tbp2, have been shown to be associated with dense OM vesicles, with IM vesicles or with vesicles of intermediate density (Pugsley, 1993). The presence of LPS, the undetected NADH oxidase (cytoplasmic membrane marker), and the greater density of the fraction containing recombinant Tbp2 in this study suggest that it represents a modified OM fraction and thus suggests that the recombinant Tbp2 has been translocated across the IM and exported to the $\mathrm{OM}$. The presence of a Ser residue immediately after the $\mathrm{N}$-terminal Cys in h49 and h171 Tbp2 receptor proteins as well as in the AP205 Tbp2 (TfbA) reported earlier (Gerlach et al., 1992b) is consistent with this localization as only lipoproteins with an Asp residue in this position have been localized to the cytoplasmic membrane in $E$. coli (Pugsley et al., 1991).

The LPS-containing membrane fraction was not evident in experiments with strains containing recombinant plasmids pBAPT1 and pBAPT2, although it was noted that the OM band was more diffuse than normal in sucrose gradients. It thus seems likely that the appearance of the modified OM band is due to self-association of the recombinant Tbp2, particularly when it is present in high concentrations. We cannot exclude the possibility that this is an intrinsic property of $\mathrm{Tbp} 2$, even though it is also possible that improper folding of recombinant Tbp2 could provide surfaces of interaction that facilitate aggregation such as observed with inclusion bodies. The failure to detect direct binding of HRP-pTf by intact cells expressing recombinant $\mathrm{Tbp} 2$ might be interpreted as a failure to attain proper folding and translocation of the Tbp2 protein in E. coli, but would have to be substantiated by comparison with an isogenic mutant of $A$. pleuropneumoniae deficient in Tbp1. The ability to affinity-isolate recombinant $\mathrm{Tbp} 2$ from the various fractions indicates that either the structures which are involved in transferrinbinding were present but 'masked' and/or that solubilization with detergent facilitated re-folding to reconstitute the binding domain. It is salient to note that, in contrast to what was observed in N. meningitidis (Irwin et al., 1993), affinity-isolation of A. pleuropneumoniae Tbp2 did not require the presence of Tbp1.
The ability to maintain or reconstitute binding activity by native Tbp2 after SDS-PAGE and electroblotting (Gonzalez et al., 1990), in conjunction with these results, indicate that binding alone is not an adequate indicator of native conformation of the Tbp2 protein. We used the proteolytic cleavage of intact proteins as an alternative procedure to assess conformation but did not detect any stable intermediates in our preliminary attempts. Thus, in the absence of functional reconstitution assays in the heterologous host, it will be difficult to make definitive conclusions regarding the proper processing and folding of recombinant Tbp2 in E. coli.

Previous studies of expression of the genes encoding meningoccocal Tbp1 (Palmer et al., 1993), gonococcal Tbp1 (Cornelissen et al., 1993) and meningococcal Lbp (Pettersson et al., 1994b) in E. coli showed that binding activity for transferrin or lactoferrin is at the surface. These results indicate that the Tbp1 and Lbp proteins were processed by the signal peptidase and exported to the $\mathrm{OM}$ where they were assembled in an apparently native state. These results have important implications regarding the possibility of heterologous genetic reconstitution studies and for the possibility of heterologous production of protein for vaccine purposes. However, the previous studies did not include analysis of the distribution of recombinant proteins in the various cell fractions to provide information on the efficiency of the processing/translocation steps. The results presented in this paper show that when the $A$. pleuropneumoniae tbp $A$ gene is expressed under the control of the T7 promoter, a proportion of the recombinant Tbp1 is found in inclusion bodies, suggesting that processing by the signal peptidase is limiting the export of Tbp1 during high-level expression. The inability to affinity-isolate $\mathrm{Tbp} 1$ from this fraction indicates that the majority of the protein is in a non-functional state which will have to be taken into account when attempting to pursue structure-function studies with the recombinant protein.

Our results demonstrate that recombinant Tbp2, as well as recombinant $\mathrm{Tbp} 1$ and native receptor, predominantly bind to the $\mathrm{C}$-lobe of porcine transferrin. These results are comparable to the observation that the regions of human transferrin that are predominantly responsible for binding to receptors on bacterial pathogens of humans ( $N$. meningitidis, $N$. gonorrboeae and $H$. infuenzae) are located on the C-lobe (Alcantara et al., 1993). We were unable to demonstrate any binding of the $A$. pleuropneumoniae receptor proteins by the $\mathrm{N}$-lobe preparation in affinity experiments or in direct or competitive-binding assays (data not shown). The identity of the C-lobe preparation used in our experiments was confirmed by the presence of the oligosaccharide side-chain (Sharma et al., 1994) and by $\mathrm{N}$-terminal sequence analysis and comparison with the predicted protein sequence derived from the cloned $\mathrm{pTf}$ cDNA (Baldwin \& Weinstock, 1988). In a previous publication, binding of $\mathrm{pTf} N$-lobe by recombinant $\mathrm{Tbp} 2$ $(\mathrm{TfbA})$ was demonstrated in a competitive ELISA which was interpreted to indicate that receptor binding was primarily mediated by regions located in the $\mathrm{N}$-lobe (Gerlach et al., 1992a) although no experiments with C- 
lobe preparations were described or discussed. The nearly identical sequence of the $t b p B$ genes in the two studies indicate that the contrasting results are unlikely to be due to intrinsic differences in the proteins themselves but are more likely a function of methodology. Since the results reported here were obtained with the native receptor as well as the recombinant proteins, we are inclined to conclude that the transferrin receptor in strains of $A$. pleuropneumoniae interacts primarily with regions in the $\mathrm{C}$ lobe.

\section{ACKNOWLEDGEMENTS}

This work was supported by funds provided by Eli Lilly and Company, and by grant MT-10350 from the Medical Research Council of Canada.

\section{REFERENCES}

Alcantara, J., Yu, R.-H. \& Schryvers, A. B. (1993). The region of human transferrin involved in binding to bacterial transferrin receptors is localized in the C-lobe. Mol Microbiol 8, 1135-1143.

Anderson, J. A., Sparling, P. F. \& Cornelissen, C. N. (1994). Gonococcal transferrin-binding protein 2 facilitates but is not essential for transferrin utilization. J Bacteriol 176, 3162-3170.

Archibald, F. S. \& DeVoe, I. W. (1979). Removal of iron from human transferrin by Neisseria meningitidis. FEMS Microbiol Lett 6, 159-162.

Baldwin, G. S. \& Weinstock, J. (1988). Nucleotide sequence of porcine liver transferrin. Nucleic Acids Res 16, 8720.

Bell, P. E., Nau, C. D., Brown, J. T., Konisky, J. \& Kadner, R. J. (1990). Genetic suppression demonstrates interaction of TonB protein with outer membrane transport proteins in Escherichia coli. J Bacteriol 172, 3826-3829.

Blanton, K. J., Biswas, G. D., Tsai, J., Adams, J., Dyer, D. W., Davis, S. M., Koch, G. G., Sen, P. K. \& Sparling, P. F. (1990). Genetic evidence that Neisseria gonorrboeae produces specific receptors for transferrin and lactoferrin. $J$ Bacteriol 172, 5225-5235.

Calderwood, S. B. \& Mekalanos, J. J. (1988). Confirmation of the Fur operator site by insertion of a synthetic oligonucleotide into an operon fusion plasmid. J Bacteriol 170, 1015-1017.

Cornelissen, C. N., Biswas, G. D., Tsai, J., Paruchuri, D. K., Thompson, S. A. \& Sparling, P. F. (1992). Gonococcal transferrinbinding protein 1 is required for transferrin utilization and is homologous to TonB-dependant outer membrane receptors. $J$ Bacteriol 174, 5788-5797.

Cornelissen, C. N., Biswas, G. D. \& Sparling, P. F. (1993). Expression of gonococcal transferrin-binding protein 1 causes Escherichia coli to bind human transferrin. J Bacteriol 175, 2448-2450.

Gerlach, G. F., Anderson, C., Potter, A. A., Klashinsky, S. \& Willson, P. J. (1992a). Cloning and expression of a transferrinbinding protein from Actinobacillus pleuropneumoniae. Infect Immun 60, 892-898.

Gerlach, G.-F., Klashinsky, S., Anderson, C., Potter, A. A. \& Willson, P. J. (1992b). Characterization of two genes encoding distinct transferrin-binding proteins in different Actinobacillus pleuropneumoniae isolates. Infect Immun 60, 3253-3261.

Gold, L. (1988). Posttranscriptional regulatory mechanisms in Escherichia coli. Annu Rev Biochem 57, 199-233.

Gonzalez, G. C., Caamano, D. L. \& Schryvers, A. B. (1990). Identification and characterization of a porcine-specific transferrin receptor in Actinobacillus pleuropneumoniae. Mol Microbiol 4, 1173-1179.
Gray-Owen, S. D., Loosemore, S. \& Schryvers, A. B. (1995). Identification and characterization of genes encoding the human transferrin binding proteins from Haemopbilus influenzae. Infect Immun 63, 1201-1210.

Greener, A. (1990). E. coli SURE ${ }^{\mathrm{TM}}$ strain: clone 'unclonable' DNA. In Strategies, vol. 3, pp. 5-6. La Jolla, CA: Stratagene Cloning Systems.

Griffiss, J. M. (1982). Epidemic meningococcal disease : synthesis of a hypothetical immunoepidemiologic model. Rev Infect Dis 4, 159-172.

Hancock, R. E. W. \& Nikaido, H. (1978). Outer membranes of Gram-negative bacteria. 19. Isolation from Pseudomonas aeruginosa and use in reconstitution and definition of the permeability barrier. $J$ Bacteriol 136, 381-390.

Harlow, E. \& Lane, D. (1988). Immunizations. In Antibodies: a Laboratory Manual, pp. 92-120. Edited by E. Harlow \& D. Lane. Cold Spring Harbor, NY: Cold Spring Harbor Laboratory.

Irwin, S. W., Averill, N., Cheng, C. Y. \& Schryvers, A. B. (1993). Preparation and analysis of isogenic mutants in the transferrin receptor protein genes, $t b p 1$ and $t b p 2$, from Neisseria meningitidis. Mol Microbiol 8, 1125-1133.

Legrain, M., Jacobs, E., Irwin, S. W., Schryvers, A. B. \& QuentinMillet, M. J. (1993). Molecular cloning and characterization of Neisseria meningitidis genes encoding the transferrin binding proteins Tbp1 and Tbp2. Gene 130, 73-80.

Litwin, C. M. \& Calderwood, S. B. (1993). Role of iron in regulation of virulence genes. Clin Microbiol Rev 6, 137-149.

Maciver, I. \& Hansen, E. J. (1994). Identification of a positive regulatory factor involved in expression of transferrin-binding activity by Haemophilus influenzae. Abstracts of 94th General Meeting of the American Society for Microbiology, Las Vegas, NV. Abstract B162.

Mickelsen, P. A., Blackman, E. \& Sparling, P. F. (1982). Ability of Neisseria gonorrboeae, Neisseria meningitidis, and commensal Neisseria species to obtain iron from lactoferrin. Infect Immun 35, 915-920.

Ogunnariwo, J. A. \& Schryvers, A. B. (1990). Iron acquisition in Pasteurella baemolytica: expression and identification of a bovinespecific transferrin receptor. Infect Immun 58, 2091-2097.

Ogunnariwo, J. A. \& Schryvers, A. B. (1992). Correlation between the ability of Haemophilus paragallinarum to acquire ovotransferrinbound iron and the expression of ovotransferrin-specific receptors. Avian Dis 36, 655-663.

Osborn, M. J., Gander, J. E., Parisi, E. \& Carson, J. (1972). Mechanism of assembly of the outer membrane of Salmonella typhimurium. J Biol Cbem 247, 3962-3972.

Palmer, H. M., Powell, N. B. L., Ala'aldeen, D. A., Wilton, J. \& Borriello, S.P. (1993). Neisseria meningitidis transferrin-binding protein 1 expressed in Escherichia coli is surface exposed and binds human transferrin. FEMS Microbiol Lett 110, 139-146.

Pettersson, A., Van Der Ley, P., Poolman, J. T. \& Tommassen, J. (1993). Molecular characterization of the 98-kilodalton ironregulated outer membrane protein of Neisseria meningitidis. Infect Immun 61, 4724-4733.

Pettersson, A., Klarenbeek, V., Van Deurzen, J., Poolman, J. T. \& Tommassen, J. (1994a). Molecular characterization of the structural gene for the lactoferrin receptor of the meningococcal strain H44/76. Microb Patbog 17, 395-408.

Pettersson, A., Maas, A. \& Tommassen, J. (1994b). Identification of the iro $A$ gene product of Neisseria meningitidis as a lactoferrin receptor. J Bacteriol 176, 1764-1766.

Pugsley, A. P. (1993). The complete general secretory pathway in gram-negative bacteria. Microbiol Rev 57, 50-108. 
Pugsley, A. P., Poquet, I. \& Kornacker, M. G. (1991). Two distinct steps in pullulanase secretion by Escherichia coli K12. Mol Microbiol 5, 865-873.

Rossi-Campos, A., Anderson, C., Gerlach, G.-F., Klashinsky, S., Potter, A. A. \& Willson, P. J. (1992). Immunization of pigs against Actinobacillus pleuropneumoniae with two recombinant protein preparations. Vaccine 10, 512-518.

Rutz, J. M., Lui, J., Lyons, J. A., Goranson, J., Armstrong, S. K., Mcintosh, M. A., Feix, J. B. \& Klebba, P. E. (1992). Formation of gated channel by a ligand-specific transport protein in the bacterial outer membrane. Science 258, 471-475.

Schryvers, A. B. \& Gray-Owen, S. (1992). Iron acquisition in Haemophilus influenzae: receptors for human transferrin. J Infect Dis 165 (suppl. 1), S103-S104.

Schryvers, A. B. \& Lee, B. C. (1989). Comparative analysis of the transferrin and lactoferrin binding proteins in the family Neisseriaceae. Can J Microbiol 35, 409-415.

Schryvers, A. B. \& Morris, L. J. (1988a). Identification and characterization of the transferrin receptor from Neisseria meningitidis. Mol Microbiol 2, 281-288.

Schryvers, A. B. \& Morris, L. J. (1988b). Identification and characterization of the human lactoferrin-binding protein from Neisseria meningitidis. Infect Immun 56, 1144-1149.

Schryvers, A. B., Irwin, S. W., Middelveen, M. J., Ogunnariwo, J. A. \& Alcantara, J. (1991). Iron acquisition in Neisseria: bacterial receptors for human transferrin and human lactoferrin in Neisseria meningitidis. In Neisseriae 1990, pp. 481-486. Edited by M. Achtman, P. Kohl, C. Marchal, G. Morelli, A. Seiler \& B. Thiesen. Berlin: Walter de Gruyter.

Sharma, N. D., Evans, R. W., Patel, K. J., Gorinsky, B., Mallet, A. I. \& Aitken, A. (1994). Evidence for the glycosylation of porcine serum transferrin at a single site located within the C-terminal lobe. Biocbim Biophys Acta 1206, 286-288.

Short, J. M., Fernandez, J. M., Sorge, J. A. \& Huse, W. D. (1988). Lambda ZAP: a bacteriophage lambda expression vector with in vivo excision properties. Nucleic Acids Res 16, 7583-7600.

Simonson, C., Brener, D. \& Devoe, I. W. (1982). Expression of a high-affinity mechanism for acquisition of transferrin iron by Neisseria meningitidis. Infect Immun 36, 107-113.

Studier, F. W., Rosenberg, A. H., Dunn, J. J. \& Dubendorff, J. W. (1990). Use of T7 RNA polymerase to direct expression of cloned genes. Methods Enzymol 185, 60-89.

Tabor, S. (1992). Expression using the T7 RNA polymerase/promoter system. In Short Protocols in Molecular Biology, pp. 16-6-16-10. Edited by F. M. Ausubel, R. Brent, R. E. Kingston, D. D. Moore, J. G. Seidman, J. A. Smith \& K. Struhl. New York: John Wiley \& Sons.

Weinberg, E. D. (1978). Iron and infection. Microbiol Rev 42, 45-66.

Received 13 February 1995; revised 16 May 1995; accepted 8 June 1995. 